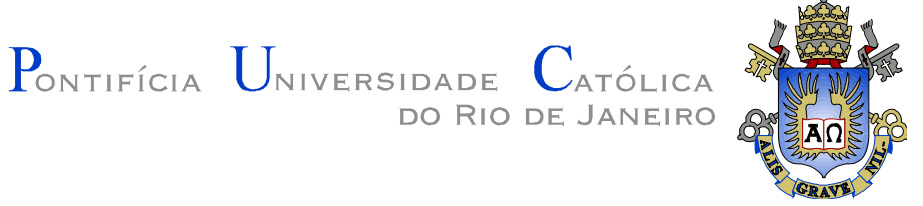

Luis Antônio Tadaiesky Barboza

Aplicação de modelos de fratura coesiva
à análise de estruturas de concreto
reforçado com fibras de aço

Dissertação de Mestrado

Dissertação apresentada como requisito parcial para obtenção do grau de Mestre pelo Programa de Pós-Graduação em Engenharia Civil do Departamento de Engenharia Civil da PUC-Rio.

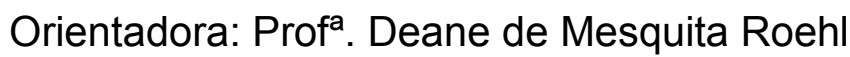

Rio de Janeiro

Fevereiro de 2015 
Luis Antônio Tadaiesky Barboza

\section{Aplicação de modelos de fratura coesiva à análise de estruturas de concreto reforçado com fibras de aço}

Dissertação apresentada como requisito parcial para obtenção do grau de Mestre pelo Programa de PósGraduação em Engenharia Civil do Departamento de Engenharia Civil do Centro Técnico Científico da PUCRio. Aprovada pela Comissão Examinadora abaixo assinada.

Prof. ${ }^{a}$ Deane de Mesquita Roehl Orientadora

Departamento de Engenharia Civil - PUC-Rio

Prof. Raul Rosas e Silva

Departamento de Engenharia Civil - PUC-Rio

Prof. Flavio de Andrade Silva Departamento de Engenharia Civil - PUC-Rio

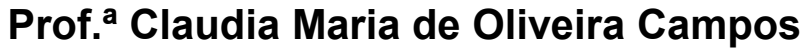
Universidade Federal Fluminense

Prof. José Eugenio Leal Coordenador Setorial do Centro Técnico Científico - PUC-Rio 
Todos os direitos reservados. É proibida a reprodução total ou Parcial do trabalho sem autorização da universidade, do autor e do orientador.

Luis Antônio Tadaiesky Barboza

Graduou-se em Licenciatura plena em Física pelo IFPA (Instituto Federal do Pará) em 2007. Graduou-se também em Engenharia Civil pela (Universidade Federal do Pará) em 2012.

Ficha Catalográfica

Barboza, Luis Antônio Tadaiesky

Aplicação de modelos de fratura coesiva à análise de estruturas de concreto reforçado com fibras de aço / Luis Antônio Tadaiesky Barboza ; orientadora: Deane de Mesquita Roehl. - 2015.

107 f. : il. (color.) ; $30 \mathrm{~cm}$

Dissertação (mestrado)-Pontifícia Universidade

Católica do Rio de Janeiro, Departamento de Engenharia Civil, 2015.

Inclui bibliografia

1. Engenharia civil - Teses. 2. Elementos finitos.

3. Zona de fratura coesiva. 4. Concreto reforçado com fibra de aço. I. Roehl, Deane de Mesquita. II. Pontifícia Universidade Católica do Rio de Janeiro. Departamento de Engenharia Civil. III. Título.

CDD: 624 


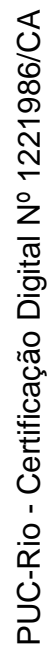

À minha avó Maria Guiomar, por todo amor e companheirismo materno. 


\section{Agradecimentos}

Primeiramente, agradeço à Deus por me conceder as ferramentas necessárias para chegar ao fim de mais um desafio em minha vida.

Agradeço à professora, Deane de Mesquita Roehl, pelo apoio, pelo conhecimento transmitido durante toda essa minha empreitada acadêmica, por toda a paciência, pela compreensão e pela amizade construída nesse período crítico.

Aos professores que participaram da banca avaliadora.

Ao professor e amigo Ivan Menezes, sempre muito solícito e com uma palavra amiga, entendendo bem as dificuldades de pessoas que saem para estudar em outras cidades tendo que ficar longe da família e amigos.

Ao Rafael Araújo, colega de turma no CEFET há muitos anos e que encontrei aqui no Rio de janeiro. Um cara que sempre veio com uma palavra incentivadora e que muito ajudou na escrita deste trabalho. Tenho o prazer de tê-lo como amigo.

Aos amigos de casa Carlos Castro e Andre Margalho. Com eles tive a lição prática de como aprender a conviver com as diferenças.

Aos amigos de PUC, Patrick Vieira, Murilo Santos, Rafael Abreu, Hélvio Peixoto, Wellington Tatagiba, Cristian Mejia, Fernando Conto, Lorena Chamorro, Magno Almeida, Marko Markini e Nilthson Noreña. Cada um destes amigos, à sua maneira, ajudaram muito durante esse árduo caminho.

Aos meus pais, Luiz Gonzaga Barboza Filho e Márcia Nazaré Barroso Tadaiesky pelo amor, confiança e todo o apoio que me foi dado. Sem vocês nada disso teria começado. Obrigado por tudo, mesmo na ausência, sei que vocês apoiam, incentivam e oram para que eu alcance o sucesso.

Aos meus irmãos, Vicente Henrique Tadaiesky Barboza e Natalia Maria Tadaiesky Barboza, pela amizade e parceria de sempre.

À minha tia Marlene Tadaiesky, meu tio Emanuel Batista e família por toda a força e acolhida nos momentos finais de meu mestrado.

À minha futura esposa Jackeline Nakata Ferreira Alves. Você foi parte fundamental em todo esse processo, desde o início, quando fomos procurar um 
apartamento para eu ficar. Obrigado por tudo, pelas vezes em que eu não estava bem e você se fazia forte para ser o meu porto seguro. Obrigado pelas críticas, pelo apoio incondicional e por todo o esforço para estar sempre ao meu lado. Sem você eu não teria terminado.

À CAPES e à PUC-Rio, pelo apoio financeiro, sem o qual este trabalho não poderia ser realizado.

Agradeço a todos aqueles que de alguma forma estiveram presentes em minha vida e me ajudaram nesse período de mestrado, desculpem-me se não citei o nome de todos aqui. 


\section{Resumo}

Barboza, Luis Antônio Tadaiesky; Roehl, Deane de Mesquita. Aplicação de Modelos de Fratura Coesiva à Análise de Estruturas de Concreto Reforçado com Fibras de Aço. Rio de Janeiro, 2015. 107p. Dissertação de Mestrado - Departamento de Engenharia Civil, Pontifícia Universidade Católica do Rio de Janeiro.

Nessa dissertação, investiga-se através do método dos elementos finitos o processo de fratura em estruturas de materiais quase frágeis com base em modelos de representação explícita de fratura por meio de elementos de fratura coesiva. Para tanto, são apresentadas duas formulações distintas de elementos finitos com base na zona de fratura coesiva. A formulação do modelo do coesivo com base no potencial PPR e a formulação dos modelos coesivos Bi-linear e Linear exponencial. As modelagens numéricas e análises são realizadas no simulador Abaqus ${ }^{\circledR}$. Essas formulações são aplicadas à simulação da evolução de trincas em corpos de prova de concreto reforçado com fibras de aço em ensaios de tração, flexão e cisalhamento. Apresentando a aplicabilidade da metodologia a problemas reais de fratura em modo I, II e em modo misto. Através dessas análises foi demostrada a aplicabilidade da formulação de zona coesiva a representação de fratura em materiais quase frágeis. O potencial PPR e o modelo Linear exponencial foram os modelos mais adequados à simulação dos ensaios em concreto reforçado com fibra de aço.

\section{Palavras-chave} fibra de aço

Elementos finitos; Zona de fratura coesiva; Concreto reforçado com 


\section{Abstract}

Barboza, Luis Antônio Tadaiesky; Roehl, Deane de Mesquita. Application of cohesive Fracture Models to the Analysis of Steelfiber Reinforced Concrete Structures. Rio de Janeiro, 2015. 107p. M.Sc. Dissertation - Departamento de Engenharia Civil, Pontifícia Universidade Católica do Rio de Janeiro.

In this thesis, the fracture process in structures with quasi-brittle materials was investigated using the finite element method based on the cohesive zone model. Two different cohesive model formulations are presented: a potential formulation, the PPR model, and a formulation for the bi-linear and linearexponential models. These formulations were applied in the simulation of fracture propagation in concrete specimens reinforced with steel-fibers. The specimens were subjected to Mode I, II and mixed-mode loading through the direct tensile, shear and bending tests. The analyses were simulated in the Abaqus $₫$. The good applicability of the cohesive zone model for fracture propagation analysis in quasi-brittle materials were demonstrated with the performed simulations. The PPR potential model and the linear-exponential model presented better results in tests with concrete reinforced with steel-fiber specimens.

\section{Keywords}

fiber

Finite element; Cohesive fracture zone; Concrete reinforced with steel 


\section{Sumário}

1 Introdução 18

$\begin{array}{ll}1.1 \text { Considerações iniciais } & 18\end{array}$

$\begin{array}{ll}1.2 \text { Objetivos e delimitações } & 21\end{array}$

$\begin{array}{ll}1.3 \text { Organização da dissertação } & 21\end{array}$

2 Mecânica da Fratura $\quad 23$

2.10 Início da Mecânica da Fratura 23

2.2 A Mecânica da Fratura Linear Elástica 24

2.3 A Mecânica da Fratura Elasto-Plástica 26

2.4 A Mecânica da Fratura Coesiva 28

2.4.1 Teoria de Dugdale para materiais dúcteis 28

2.4.2 Teoria de Barenblatt para materiais frágeis 30

2.4.3 Modelo Polinomial de Needleman 32

2.4.4 Modelo Exponencial/Polinomial de Needleman 33

2.4.5 Modelo Exponencial/Periódico de Needleman 35

2.4.6 Modelo Polinomial de Tvergaard 37

2.4.7 Modelo Multilinear com Potencial de Tvergaard e Hutchinson 39

2.4.8 Modelo Exponencial/Exponencial de Xu e Needleman 40

3 Concreto Autoadensável Reforçado com Fibras de Aço 43

3.1 Motivação para o estudo do CAAF 43

3.2 Caracterização dos materiais constituintes do CAAF 44

3.2.1 Agregados 44

3.2.2 Aglomerantes $\quad 45$

3.2.3 Superplastificantes $\quad 46$

$\begin{array}{ll}\text { 3.2.4 Agente Modificador de Viscosidade } & 47\end{array}$

3.2.5 Fibras de Aço $\quad 47$

3.3 Produção e Métodos de Ensaios $\quad 48$

3.3.1 Comportamento à Tração Direta 49

3.3.2 Comportamento ao Cisalhamento $\quad 51$

3.3.3 Comportamento à Flexão 53

$\begin{array}{ll}3.4 \text { Propriedades Mecânicas } & 54\end{array}$ 
3.4.1 Tração Direta $\quad 54$

3.4.2 Cisalhamento $\quad 55$

3.4.3 Flexão $\quad 57$

4 Formulação Matemática dos Modelos de Fratura Coesiva 59

4.1 Comportamento geral de modelos com base em zona coesiva 59

4.2 Formulação em Elementos Finitos $\quad 60$

4.3 Modelo Polinomial de Zona Coesiva com base no Potencial PPR (Park-

Paulino-Roesler) $\quad 62$

4.3.1 Considerações iniciais $\quad 62$

4.3.2 Determinação dos parâmetros do modelo coesivo PPR 63

4.4 Modelo Polinomial de fratura coesiva Bi-linear e Linear exponencial 66

4.4.1 Considerações iniciais 66

4.4.2 Determinação dos parâmetros dos elementos coesivos Bi-linear e Linear

$\begin{array}{ll}\text { exponencial } & 68\end{array}$

5 Modelagem e Resultados $\quad 72$

$\begin{array}{ll}5.1 \text { Controles da análise } & 72\end{array}$

5.2 Análise computacional de fratura em um corpo de prova submetido à $\begin{array}{ll}\text { esforço de tração } & 73\end{array}$

$\begin{array}{ll}\text { 5.2.1 Modelagem do corpo de prova } & 73\end{array}$

5.3 Análise computacional de fratura em um corpo de prova submetido à esforço de cisalhamento 78

$\begin{array}{ll}\text { 5.3.1 Modelagem do corpo de prova } & 78\end{array}$

5.4 Análise computacional de fratura em um corpo de prova submetido ao teste de flexão de quatro pontos $\quad 84$

5.4.1 Modelagem do corpo de prova $\quad 84$

5.5 Análise computacional de fratura em um corpo de prova em modo misto 95

5.5.1 Modelagem do corpo de prova 95

6 Conclusões e Sugestões 101

6.1 Conclusões 101

6.2 Sugestões para trabalho futuros 103

7 Referências Bibliográficas 104 


\section{Lista de figuras}

Figura 1.1: Acidente gerado por fadiga - propagação de uma micro trinca de forma lenta até atingir um tamanho crítico, gerando assim a fratura. 18

Figura 1.2: Trincas a partir de recalque da estrutura. 19

Figura 2.1: Modos básicos de deformação de uma trinca. 25

Figura 2.2: Fratura sob modo misto I-II: (a) configuração de carregamento; (b) tensões atuantes na fratura (Whittaker et al. 1992). 26

Figura 2.3: Conceito de CTOD. $\quad 27$

Figura 2.4: Modelo de Dugdale: (a) Geometria da região de fraturamento efetivo,

(b) Sistemas de forças atuantes durante a evolução da fratura. 29

Figura 2.5: Modelo do contorno da Superfície fraturada na Teoria de Barenblatt.

Figura 2.6: Tensões coesivas da interface em um processo de separação puramente normal.

Figura 2.7: Comparativo entre as tensões coesivas normais para um processo puramente normal para os potenciais polinomial Needleman (1987) e o exponencial/polinomial Needleman (1990a). 34

Figura 2.8: Tensões coesivas normais na interface para um processo de separação puramente normal. 36

Figura 2.9: Tensões coesivas tangenciais na interface para um processo de separação puramente tangencial. 36

Figura 2.10: Tensões coesivas normais na interface para um processo $\begin{array}{ll}\text { puramente normal. } & 38\end{array}$

Figura 2.11: Tensões tangenciais na interface para um processo de separação $\begin{array}{ll}\text { puramente tangencial. } & 38\end{array}$

Figura 2.12: Lei de separação da interface para deslocamentos efetivos. $\quad 40$

Figura 2.13: Tensões coesivas na interface para um processo de separação puramente normal.

Figura 2.14: Tensões coesivas na interface para um processo de separação puramente tangencial. 42

Figura 3.1: Curvas granulométricas dos agregados. $\quad 45$

Figura 3.2: Curvas granulométricas da sílica ativa, da cinza volante e do cimento CP II 40.

Figura 3.3: Agente modificador de viscosidade Rheomac UW 410. 
$\begin{array}{ll}\text { Figura 3.4: Fibras de aço utilizadas } & 48\end{array}$

Figura 3.5: Sistema rígido utilizado para os ensaios de tração direta. 49

Figura 3.6: Tração direta, dimensões da amostra. $\quad 50$

Figura 3.7: Sistema de colagem das amostras para garantir o alinhamento. $\quad 50$

Figura 3.8: Configuração do ensaio de tração direta para amostras prismáticas.

Figura 3.9: Instrumentação dos corpos-de-prova para ensaios de cisalhamento.

Figura 3.10: Dimensões da peça ensaiada no ensaio de cisalhamento. 52

Figura 3.11: Aparato para ensaio de flexão. 53

Figura 3.12: Curva típica, obtida no ensaio de tração para o concreto fibroso do tipo C2: Tensão x Deformação e Tensão x Abertura de fissura. 55

Figura 3.13: Pontos de análise da curva carga-deslocamento obtida do ensaio de resistência ao cisalhamento. 56

Figura 3.14: Curva típica carga $x$ deslocamento obtida do ensaio de cisalhamento do concreto C2.1\%65. 57

Figura 3.15: Curva típica Carga x Deslocamento do concreto C2.1\%65. 58

Figura 4.1: Lei constitutiva de tensão coesiva x separação. 60

Figura 4.2: Corpo em estudo. 61

Figura 4.3: Elemento de fratura coesiva. 61

Figura 4.4: Caracterização do tipo de amolecimentos a partir dos parâmetros de forma. $\quad 64$

Figura 4.5: Lei constitutiva para o modelo coesivo Bi-linear para modo I. $\quad 67$

Figura 4.6: (a) Modelo constitutivo Bi-linear, (b) Modelo constitutivo Linear $\begin{array}{ll}\text { exponencial. } & 69\end{array}$

Figura 4.7: Diagrama da resposta do elemento Bi-linear em modo misto. $\quad 71$

Figura 5.1: Peça modelada.

Figura 5.2: Distribuição de deslocamentos horizontais U1. 75

Figura 5.3: Distribuição das Tensões de von Mises. $\quad 75$

Figura 5.4: distribuição das Tensões S11. 76

Figura 5.5: Curva tensão x abertura de fissura. 76

Figura 5.6: Tensão x Deformação.

Figura 5.7: Modelo computacional do corpo-de-prova. $\quad 79$

Figura 5.8: Região de zona coesiva. $\quad 79$

Figura 5.9: Distribuição dos deslocamentos verticais U2. 80

Figura 5.10: Distribuição das tensões de von Mises. 81 
Figura 5.11: Distribuição das tensões S22.

Figura 5.12: Curva Carga x deslocamento vertical 82

Figura 5.13: Curva Tensão x deslocamento vertical. 83

Figura 5.14: Modelo computacional do corpo-de-prova. 85

Figura 5.15: Distribuição dos deslocamentos verticais. 86

Figura 5.16: Distribuição das tensões de von Mises. 87

Figura 5.17: Distribuição das tensões S11. 87

Figura 5.18: Distribuição do dano ao longo da zona onde se processa a fratura.

Figura 5.19: Carga x deslocamento vertical para o modelo Bi-linear. 89

Figura 5.20: Carga $x$ deslocamento vertical para o modelo Linear exponencial. 89

Figura 5.21: Carga x deslocamento vertical para o modelo PPR. 90

Figura 5.22: Curva Força aplicada x deslocamento vertical 91

Figura 5.23: Tensão $x$ deslocamento vertical 92

Figura 5.24: Ensaio de corpos-de-prova em flexão à três pontos de vigas entalhadas.

Figura 5.25: Carga x CMOD.

Figura 5.26: Modelos de fratura DCB, MMB E ENF. 96

Figura 5.27: Modo misto de fratura, modelo teórico. 96

Figura 5.28: Deformada da Viga solicitada em modo misto. 98

Figura 5.29: (a) Tensão normal x Deslocamento normal, (b) Tensão tangencial x Deslocamento tangente. 99

Figura 5.30: Carga aplicada x Abertura da boca da trinca $(\mu)$. 


\section{Lista de tabelas}

Tabela 1: Características das fibras de aço utilizadas, Marangon (2011).

Tabela 2: Resultados de resistência à tração, deformação de pico e módulo de elasticidade, referente ao concreto C2.1\%65, Marangon (2011).

Tabela 3: Resultados de tensão de cisalhamento e de deslocamento de pico referentes aos pontos $\mathrm{P} 1, \mathrm{P} 2, \mathrm{Pu}, \mathrm{P} 3, \mathrm{P} 4$ e $\mathrm{P} 5$, para o concreto $\mathrm{C} 2.1 \% 65$, Marangon (2011).

Tabela 4: Resultados de tensão e deslocamento de primeira fissura, resistência à compressão e deslocamento de pico (ruptura) do concreto C2.1\%65, Marangon (2011).

Tabela 5: Propriedades e parâmetros utilizados nos modelos constitutivos Bilinear e Linear exponencial para tração.

Tabela 6: Propriedades e parâmetros utilizados no modelo constitutivo PPR para tração.

Tabela 7: Tensões máximas e deformações.

Tabela 8: Propriedades e parâmetros utilizados nos modelos constitutivos Bilinear e Linear exponencial o cisalhamento.

Tabela 9: Propriedades e parâmetros utilizados no modelo constitutivo PPR para o cisalhamento.

Tabela 10: Cargas máximas e deslocamentos medidos numericamente 82

Tabela 11: Tensões máximas e deslocamentos. 83

Tabela 12: Características dos corpos-de-prova modelados.

Tabela 13: Propriedades e parâmetros utilizados nos modelos constitutivos Bilinear e Linear exponencial para flexão.

Tabela 14: Propriedades e parâmetros utilizados no modelo constitutivo PPR para flexão.

Tabela 15: Carga aplicada e deslocamentos.

Tabela 16: Tensões máximas e deslocamentos. 92

Tabela 17: Carga aplicada e deslocamentos. 94

Tabela 18: Propriedades adotadas para o material. 97

Tabela 19: Propriedades e parâmetros utilizados nos modelos constitutivos $\mathrm{Bi}$ linear e Linear exponencial para o modo misto.

Tabela 20: Propriedades e parâmetros utilizados no modelo constitutivo PPR para o modo misto 


\section{Lista de símbolos}

\begin{tabular}{|c|c|}
\hline$a$ & Comprimento da trinca \\
\hline$a_{e f}$ & Comprimento efetivo da trinca \\
\hline $\bar{\alpha}$ & $\begin{array}{l}\text { Coeficiente de cisalhamento relativo à rigidez normal da } \\
\text { interface }\end{array}$ \\
\hline$\alpha_{e}$ & Coeficiente de encruamento \\
\hline$\alpha, \beta$ & Parâmetros de forma do modelo coesivo PPR \\
\hline $\bar{\beta}$ & Parâmetro de cisalhamento \\
\hline$\tilde{\beta}$ & $\begin{array}{l}\text { Distância do plano de fratura ao contorno da superfície } \\
\text { fraturada }\end{array}$ \\
\hline$d$ & Comprimento da ponta da trinca na Teoria de Barenblatt \\
\hline$D$ & Variável de dano dos modelos Bi-linear e Linear exponencial \\
\hline$\delta$ & Comprimento característico do modelo de zona coesiva. \\
\hline$\varphi$ & Parâmetro de forma do modelo coesivo Linear exponencial \\
\hline$\Phi_{n}$ & Trabalho de separação normal \\
\hline$\Phi_{t}$ & Trabalho de separação tangente \\
\hline$G$ & Força de extensão da trinca \\
\hline$G_{C}$ & Energia liberada no processo de fratura \\
\hline$G_{I C}$ & Energia liberada no processo de fratura em modo I \\
\hline$G_{I I C}$ & Energia liberada no processo de fratura em modo II \\
\hline$\eta$ & Parâmetro adimensional de controle \\
\hline$G_{I}$ & $\begin{array}{l}\text { Energia em modo I a cada incremento de da análise dos } \\
\text { modelos Bi-linear e Liner-exponecial }\end{array}$ \\
\hline$G_{I I}$ & $\begin{array}{l}\text { Energia em modo II a cada incremento de da análise dos } \\
\text { modelos Bi-linear e Liner-exponecial }\end{array}$ \\
\hline$\delta_{m}$ & Deslocamento efetivo resultante \\
\hline$\delta_{n c}$ & Abertura crítica normal \\
\hline$\delta_{t c}$ & Abertura crítica tangente \\
\hline
\end{tabular}


$\delta_{n} \quad$ Abertura normal para separação completa

$\delta_{t} \quad$ Abertura tangente para separação completa

$\bar{\delta}_{n} \quad$ Comprimento característico do modelo de zona coesiva na direção normal

$\bar{\delta}_{t} \quad$ Comprimento característico do modelo de zona coesiva na direção tangencial

$\delta \varepsilon \quad$ Deformações virtuais

$\delta u \quad$ Deslocamentos virtuais

$\delta \Delta \quad$ Abertura da trinca virtual

$\Delta \quad$ Separação normal ao longo da superfície de fratura ou ao longo da zona de fratura coesiva.

Separação tangente ao longo da superfície de fratura ou ao $\Delta_{t} \quad$ longo da zona de fratura coesiva.

Módulo de elasticidade longitudinal ou Módulo de Young

Deformação

Função generalizada das tensões coesivas do modelo de Tvergaard

$\phi_{n} \quad$ Energia de fratura normal no modelo coesivo PPR

Energia de fratura tangente no modelo coesivo PPR

$J \quad$ Integral $J$

Constantes dos modelos de Hutchinson, Rice e Rosengren

$K_{0}$

Rigidez de penalidade nos modelos Bi-linear e Linear exponencial

$K \quad$ Fator de Intensidade de Tensão

$K_{t} \quad$ Fator de Concentração de Tensão

$\lambda_{n} \quad$ Indicador de inclinação normal do modelo coesivo PPR

$\lambda_{t} \quad$ Indicador de inclinação tangente do modelo coesivo PPR

$\bar{\lambda} \quad$ Deslocamento efetivo do modelo de Tvergaard

$m, n \quad$ Constantes adimensionais do modelo PPR

ne Expoente de encruamento 


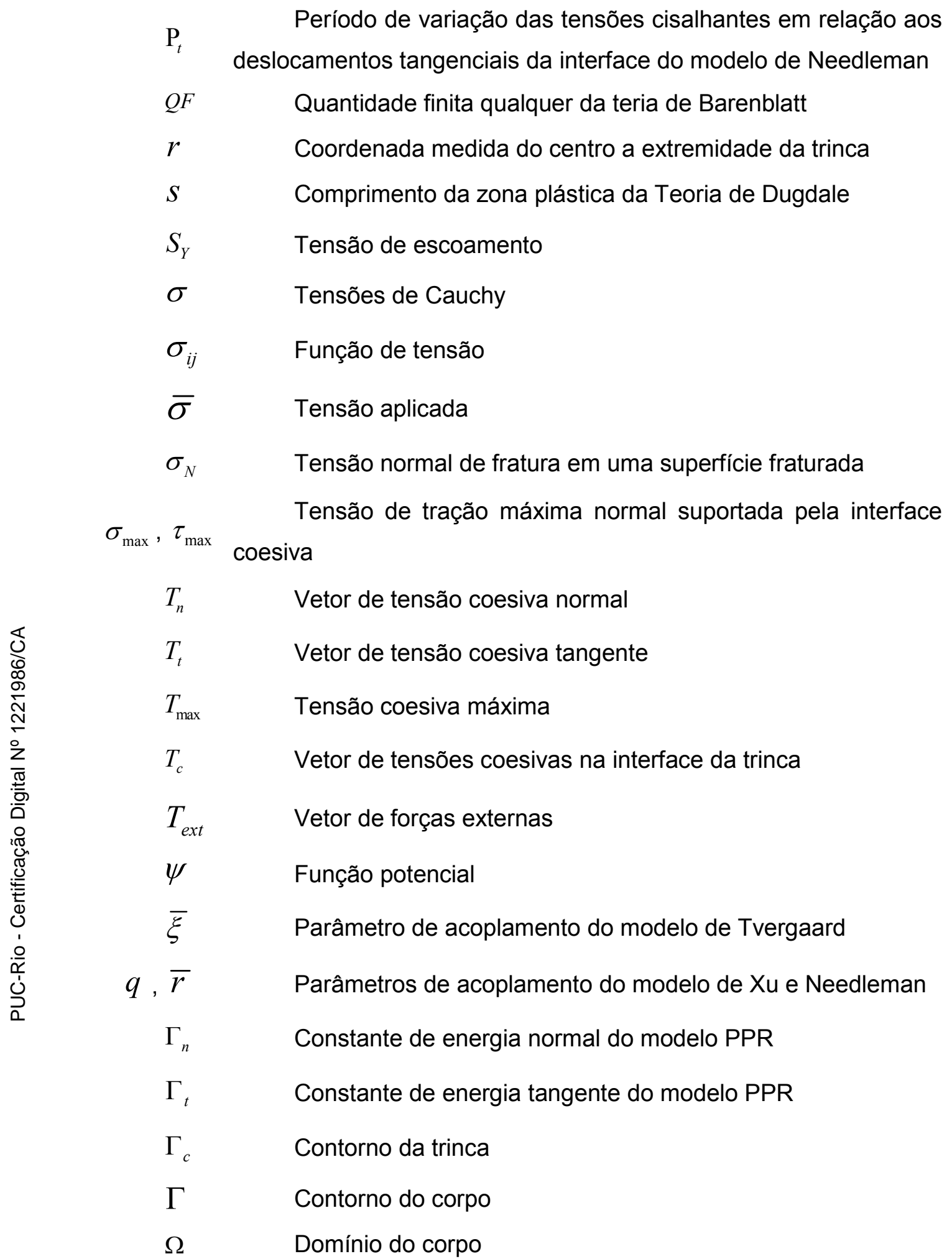

